\title{
Depressed levels of dehydroepiandrosterone sulphate in postmenopausal women with rheumatoid arthritis but no relation with axial bone density
}

\author{
G M Hall, L A Perry, T D Spector
}

\begin{abstract}
The sex hormones dehydroepiandrosterone sulphate (DHEAS), oestradiol, and sex hormone binding globulin (SHBG) were measured in 185 postmenopausal women (aged 45-65 years) with rheumatoid arthritis (RA) and related to assessments of bone mineral density at the spine and proximal femur. Compared with 518 postmenopausal control women (aged 45-65 years), DHEAS levels were below normal in the 120 patients with $R A$ who had never taken corticosteroids and levels were further depressed in 39 patients currently using steroids. Twenty six patients who had completed steroid treatment also had lower DHEAS levels, suggesting a delayed recovery of adrenal androgen secretion. Oestradiol and SHBG levels were similar in all groups. There was no correlation between sex hormones and disease activity. Oestradiol correlated with bone mineral density at all sites. Although oestradiol correlated with DHEAS, there was no relation between DHEAS and bone mineral density. The cause of below normal levels of DHEAS in $R A$ is unclear, whether a consequence of chronic illness, immune dysfunction, or a defect of adrenal androgen synthesis.
\end{abstract}

(Ann Rheum Dis 1993; 52: 211-214)

There has been considerable interest in the role of sex hormones in the aetiopathogenesis of rheumatoid arthritis (RA), based on the observed effects of gender, pregnancy, and exogenous oestrogens on the disease. Defective androgen synthesis in men and women has been proposed as a potential predisposing factor for RA, ${ }^{1}$ though others suggest low androgen levels to be a secondary phenomenon of chronic disease. ${ }^{23}$ Studies of dehydroepiandrosterone sulphate (DHEAS) levels in women with RA have yielded conflicting results; decreased, increased, and normal levels have been reported. ${ }^{4-7}$ Dehydroepiandrosterone sulphate is the most abundant androgen in normal postmenopausal women and despite being linked with atherosclerosis, diabetes, and hyperlipidaemia, ${ }^{8}$ its role remains to be established. Other studies have suggested that DHEAS may be important in maintaining skeletal mass in normal women ${ }^{9-11}$ and in women with RA. ${ }^{5}$ Most of these studies have used small numbers of patients and often inappropriate control groups. The aims of this study were to assess sex hormone status and the relation with bone density in a large group of postmenopausal women with $\mathrm{RA}$ and matched controls. Based on previous work, we decided to examine three sex steroids in detail: DHEAS, as the most abundant androgen; oestradiol, as the most active oestrogen; and sex hormone binding globulin (SHBG), a carrier protein that is a marker of free androgen and oestrogen.

\section{Patients and methods}

One hundred and eighty five postmenopausal women (aged 45-65 years) with definite RA were recruited from five rheumatology centres in northeast London. Patients were defined as postmenopausal if their last menstrual period had been more than one year ago or follicle stimulating hormone was greater than 15 IU/l. Exclusion criteria included present use of hormone replacement therapy (HRT) and concurrent illnesses that might affect bone mass.

All assessments of disease activity were made by the same observer and included the Ritchie articular index, Health Assessment Questionnnaire (HAQ), early morning stiffness, 10 $\mathrm{cm}$ visual analogue pain scale, and the erythrocyte sedimentation rate (ESR). Details of previous and current steroid treatment were recorded according to medical records, treatment cards, and patient recollection. Cumulative dose was calculated from the mean daily dose multiplied by the number of months of treatment.

Blood samples were taken at the same time of day in each patient (1400-1600 hours). Serum concentrations of oestradiol, SHBG, and DHEAS were measured using radioimmunoassay with a coefficient of variation of less than $10 \%$. Bone density was measured at the lumbar spine $\mathrm{L} 1-\mathrm{L} 4$ and proximal femur using dual energy $x$ ray absorptiometry (Hologic QDR 1000/W). In 53 consecutive patients whole body bone density was also measured.

The control group consisted of 518 postmenopausal women (aged 45-65 years) who agreed to participate in a population
Dr Hall.

Accepted for publication 3 November 1992 
Table 1 Characteristics of patients with rheumatoid arthritis (RA) and controls

\begin{tabular}{|c|c|c|c|c|}
\hline \multirow[b]{2}{*}{ Mean (SD) variable } & \multicolumn{3}{|c|}{ Patients with $R A$} & \multirow[b]{2}{*}{$\begin{array}{l}\text { Controls } \\
(n=518)\end{array}$} \\
\hline & $\begin{array}{l}\text { Never steroids } \\
(n=120)\end{array}$ & $\begin{array}{l}\text { Ex steroids } \\
(n=26)\end{array}$ & $\begin{array}{l}\text { Current steroids } \\
(n=39)\end{array}$ & \\
\hline $\begin{array}{l}\text { Age (years) } \\
\text { Years since menopause } \\
\text { Weight (kg) } \\
\text { Disease duration (years) } \\
\text { Health Assessment Questionnaire score } \\
\text { Ritchie articular index } \\
\text { Erythrocyte sedimentation rate (mm/hour) } \\
\text { Early morning stiffness (min) }\end{array}$ & $\begin{array}{l}56 \cdot 0(5 \cdot 0) \\
8 \cdot 3(6 \cdot 1)^{\star} \\
65 \cdot 9(11 \cdot 8) \\
11 \cdot 2(8 \cdot 3) \\
1 \cdot 3(0 \cdot 8) \\
10 \cdot 4(8 \cdot 5) \\
32 \cdot 6(22 \cdot 9) \\
40 \cdot 2(45 \cdot 0)\end{array}$ & $\begin{array}{l}56 \cdot 1(4 \cdot 9) \\
5 \cdot 5(4 \cdot 8) \dagger \\
61 \cdot 5(10 \cdot 2) \ddagger \\
13 \cdot 1(10 \cdot 5) \\
2 \cdot 0(0 \cdot 7) \ddagger \\
13 \cdot 1(9 \cdot 1) \\
30 \cdot 3(24 \cdot 3) \\
43 \cdot 7(55 \cdot 2)\end{array}$ & $\begin{array}{l}57 \cdot 7(5 \cdot 1) \\
9 \cdot 1(6 \cdot 1) \\
64 \cdot 2(12 \cdot 2) \\
13 \cdot 8(12 \cdot 2) \\
1 \cdot 6(0 \cdot 9) \\
12 \cdot 3(10 \cdot 4) \\
40 \cdot 9(26 \cdot 6) \\
43 \cdot 7(39 \cdot 3)\end{array}$ & $\begin{array}{c}56 \cdot 8(5 \cdot 2) \\
9 \cdot 0(5 \cdot 1) \\
67 \cdot 2(11 \cdot 5)\end{array}$ \\
\hline
\end{tabular}

*Never steroids $v$ ex steroids $(\mathrm{p}=0.03)$.

†Ex steroids $v$ current steroids $(\mathrm{p}<0.01)$,

$\ddagger$ Ex steroids $v$ never steroids $(\mathrm{p}<0.001)$.

screening programme for bone and joint disease and had never received HRT.

In view of the known effects of corticosteroids on bone and sex hormones, patients were analysed by three groups: those who had never taken steroids (never users, 120 women), those who had taken steroids in the past (ex users, 26 women), and those currently maintained on steroids (current users, 39 women). Serum hormone concentrations showed a non-normal distribution and statistical analyses were made using Student's $t$ test following logarithmic transformation of the data. Levels of oestradiol and DHEAS below the sensitivity of the assays were given a value equal to the lowest recordable concentration $(20 \mathrm{pmol} / 1$ and $0.2 \mu \mathrm{mol} / 1$ respectively). Variables were compared using Pearson's correlation test.

\section{Results}

Table 1 lists the disease characteristics of the three RA groups and the controls. The current steroid users, never users, and controls were similar in age, years since the menopause, and weight. There were no significant differences in parameters of disease activity. Compared with

Table 2 Hormone concentrations in patients with rheumatoid arthritis $(R A)$ and control groups. Note all statistical comparisons based on log transformed data.

\begin{tabular}{|c|c|c|c|c|}
\hline \multirow[b]{2}{*}{ Mean (SD) variable } & \multicolumn{3}{|c|}{ Patients with $R A$} & \multirow[b]{2}{*}{$\begin{array}{l}\text { Controls } \\
(n=518)\end{array}$} \\
\hline & $\begin{array}{l}\text { Never steroids } \\
(n=120)\end{array}$ & $\begin{array}{l}\text { Ex steroids } \\
(n=26)\end{array}$ & $\begin{array}{l}\text { Current steroids } \\
(n=39)\end{array}$ & \\
\hline $\begin{array}{l}\text { DHEAS }(\mu \mathrm{mol} / 1)^{\star} \\
\text { SHBG }(\mathrm{nmol} / /)^{\star} \\
\text { Oestradiol }(\mathrm{pmol} / \mathrm{l})\end{array}$ & $\begin{array}{l}3 \cdot 06(3 \cdot 57) \dagger \\
57 \cdot 6(26 \cdot 9) \\
81 \cdot 4(150 \cdot 5)\end{array}$ & $\begin{array}{l}1 \cdot 73(1 \cdot 74) \ddagger \\
66 \cdot 4(32 \cdot 1) \\
65 \cdot 6(159 \cdot 8)\end{array}$ & $\begin{array}{l}1 \cdot 13(1 \cdot 09) \\
49 \cdot 3(19 \cdot 8) \\
48 \cdot 1(80 \cdot 6)\end{array}$ & $\begin{array}{l}3 \cdot 93(3 \cdot 53) \\
57 \cdot 3(27 \cdot 3) \\
52 \cdot 8(105 \cdot 8)\end{array}$ \\
\hline
\end{tabular}

^DHEAS=dehydroepiandrosterone sulphate; SHBG=sex hormone binding globulin tp<0.001, never steroids $v$ controls; never steroids $v$ current steroids.

$\neq \mathrm{p}<0.02$, never steroids $v$ ex steroids.

Table 3 Correlations ( $r$ values) between sex hormones, disease characteristics, and bone mineral density in patients with rheumatoid arthritis who have never used steroids

\begin{tabular}{|c|c|c|c|}
\hline & Oestradiol & $S H B G^{\star}$ & $D H E A S^{*}$ \\
\hline Age & $-0.55 t$ & $-0 \cdot 11$ & $-0 \cdot 31 \neq$ \\
\hline Years since menopause & $-0.45 t$ & $-0 \cdot 13$ & $-0 \cdot 24 \ddagger$ \\
\hline Weight & -0.1 & $-0.41 \neq$ & $-0.09+$ \\
\hline Health Assessment Questionnaire & $-0 \cdot 17$ & $-0 \cdot 10^{+}$ & $-0 \cdot 10$ \\
\hline Ritchie articular index & $-0 \cdot 12$ & $-0 \cdot 14$ & $-0 \cdot 13$ \\
\hline Early morning stiffness & $-0 \cdot 16$ & -0.12 & -0.13 \\
\hline Visual analogue pain scale & $-0 \cdot 11$ & -0.03 & $-0 \cdot 13$ \\
\hline Erythrocyte sedimentation rate & $-0 \cdot 17$ & $-0 \cdot 1$ & $-0 \cdot 13$ \\
\hline Bone mineral density spine & $0 \cdot 28 \ddagger$ & 0.005 & $0 \cdot 11$ \\
\hline Bone mineral density femur & $0 \cdot 29 \neq$ & -0.09 & 0.06 \\
\hline Bone mineral density whole body & $0.42 \ddagger$ & $0 \cdot 12$ & -0.04 \\
\hline
\end{tabular}

^DHEAS=dehydroepiandrosterone suphate; $S H B G=$ sex hormone binding globulin . $\dagger \mathrm{p}<0.001$ never users, ex users were significantly lighter $(\mathrm{p}<0.001)$, had a later menopause $(\mathrm{p}=0.03)$, and had a higher HAQ score $(p<0.001)$.

The serum concentration of DHEAS was significantly lower in all RA groups compared with controls $(p<0.001)$ (table 2). Lowest values were seen in the current users $(p<0.001$ $v$ never users), and even ex users had significantly decreased levels compared with never users $(p=0.02)$. Log SHBG and oestradiol values in the never users and steroid users were similar to controls. The DHEAS level did not correlate significantly with any of the parameters of disease activity (table 3 ), but did correlate with oestradiol $(r=0.38 ; p<0.001)$ and was inversely related to age $(r=-0.31$; $\mathrm{p}<0.01$ ).

Bone mineral density values have been discussed in detail elsewhere ${ }^{12}$ and are as follows: lumbar spine controls $0.93 \mathrm{~g} / \mathrm{cm}^{2}$, never users $0.92 \mathrm{~g} / \mathrm{cm}^{2}$, ex users $0.93 \mathrm{~g} / \mathrm{cm}^{2}$, current users $0.85 \mathrm{~g} / \mathrm{cm}^{2}$; proximal femur controls $0.87 \mathrm{~g} / \mathrm{cm}^{2}$, never users $0.81 \mathrm{~g} / \mathrm{cm}^{2}$, ex users $0.79 \mathrm{~g} / \mathrm{cm}^{2}$, current users $0.74 \mathrm{~g} / \mathrm{cm}^{2}$. There was no relation between DHEAS and bone mineral density at either measured site. Concentrations of oestradiol were inversely related to years since the menopause $(r=-0.45$; $\mathrm{p}<0.001)$ and age $(\mathrm{r}=-0.55 ; \mathrm{p}<0.001)$ as expected, but not weight. There were consistent correlations between oestradiol and bone mineral density at all sites. The SHBG level did not correlate with other hormones or with bone mineral density. The SHBG levels decreased with increased weight $(r=-0.41$; $\mathrm{p}<0.001$ ), and this relation was also seen in controls.

\section{Discussion}

The possible role of androgens as disease mediators in RA has attracted particular interest as subnormal levels have been consistently reported in men with $\mathrm{RA},{ }^{13-15}$ though levels in women are less conclusive. Dehydroepiandrosterone sulphate is the most abundant circulating androgen in postmenopausal women and exists as a large circulating pool formed principally by the peripheral sulphation of dehydroepiandrosterone (DHEA), with which it can be interconverted. ${ }^{16}$ Dehydroepiandrosterone is secreted by the adrenal cortex under the control of adrenocorticotrophic hormone ${ }^{17}$ and, to a much lesser extent, by the postmenopausal ovary. ${ }^{18}$ Labelling studies suggest DHEAS may 
be interchangeable with other androgens such as androstenedione, ${ }^{1619}$ itself an important source of postmenopausal oestrogen. ${ }^{20}$ Low DHEA and DHEAS levels have been reported in patients with postmenopausal osteoporosis 9 and correlations found with bone density in normal $^{1011}$ and rheumatoid subjects. ${ }^{5}$ Androgens may have important effects on immunological pathways. Daynes et al reported that DHEA enhances the synthesis of interleukin 2 by helper $\mathrm{T}$ cells ${ }^{21}$ and Risdon $e t$ al found that DHEA inhibited murine natural killer cell differentiation. ${ }^{22}$

Androgen status in women with RA has previously been examined in a number of small studies. Masi et al found subnormal basal excretion of 17 ketosteroids, especially DHEAS, a blunted response to ACTH, and a failure to increase excretion following metyrapone, leading them to conclude that there may be a primary defect of androgen synthesis in RA. ${ }^{1}$ Urine excretion studies may also reflect abnormalities of hormone degradation, however, and subnormal 17 ketosteroid urine excretion rates have also been found in patients with gout and diabetes. ${ }^{3}$ Studies of serum androgens in women with RA have yielded conflicting results. Feher et al reported lower levels of testosterone and DHEAS in 77 women with RA (47 postmenopausal) and also found a negative correlation between DHEAS and disease activity. ${ }^{6}$ Sambrook et al found subnormal DHEAS levels in 27 postmenopausal women who were not taking steroids but levels did not correlate with disease duration or functional class. ${ }^{5}$ Conversely, a small Italian study of 14 postmenopausal patients with RA found increased levels of DHEAS, testosterone, and androstenedione ${ }^{8}$ compared with 12 controls and another study found normal androgen levels in 19 postmenopausal patients with RA. ${ }^{7}$ Interestingly, the latter two studies used patients with osteoarthritis as controls and DHEAS levels were considerably lower in these two control groups than in our own normal population. Furthermore, some patients with osteoarthritis may themselves be hormonally different. ${ }^{23}$

Our data are derived from a substantially larger group of patients with RA and controls than previously examined, and confirm that DHEAS levels are subnormal. Whether this observation is a primary or secondary event in $\mathrm{RA}$ is unclear. It has been previously shown that chronic diseases may interfere with androgen metabolism. ${ }^{2}{ }^{3}$ Semple et al looked at 32 men with acute and long term illnesses and found that DHEAS levels only became decreased in patients who had been ill for at least two weeks. ${ }^{2}$ Patients with chronic illness are usually receiving drugs and clearly drug treatment may be a possible confounder in studies of peripheral metabolic pathways. Although it seems likely that levels of DHEAS should be influenced by the effect of disease on peripheral metabolism, we were unable to find a clear relation between DHEAS and disease activity even with large study numbers. A defect of androgen synthesis in RA, with consequent effects on immune mechanisms, remains a possible explanation for our results. This adrenal defect has been postulated as primary, ${ }^{12}$ though some work has suggested a primary defect of the hypothalamus in RA. ${ }^{24}$

In contrast with Sambrook et al, ${ }^{5}$ we were unable to find a correlation between bone density and DHEAS. Sambrook et al reported that DHEAS was a significant predictor of bone density at the femoral neck but not the lumbar spine. A number of population studies have also found weak relations between osteoporosis and DHEAS. Spector et al reported a correlation between DHEAS and spinal but not femoral bone mass ${ }^{10}$ and Nordin et al found lower DHEAS levels in women with postmenopausal fractures but no significant correlation between bone mass and DHEAS. ${ }^{9}$ Another study of postmenopausal women correlated DHEAS with forearm bone mass and vitamin $\mathrm{D}$ levels, but the two relations became insignificant after adjustment for age. ${ }^{11}$

Serum oestradiol levels in the RA and control groups were similar, confirming the findings of previous smaller studies. ${ }^{5825}$ Levels were often below the detectable range of the assay and results should therefore be interpreted cautiously-nevertheless, oestradiol correlated with bone mineral density at all sites, confirming its importance in the maintenance of the postmenopausal skeleton. There was a significant correlation between oestradiol and DHEAS. Taelman et al showed a relation between DHEA and oestrone ${ }^{11}$ and others have shown interconversion of DHEAS with other androgens, ${ }^{16}{ }^{21}$ suggesting that the DHEAS pool may help provide androgen substrate for conversion to oestrogens. This may be an explanation for the previously described relations between DHEAS and bone mass.

Current steroid users showed further decreases of DHEAS levels, likely to be a direct result of reduced ACTH dependent secretion of DHEA, as previously shown. ${ }^{1726} 27$ Oestradiol levels were not suppressed by prednisolone, probably reflecting continued secretion of ovarian androgens. ${ }^{17} 28$ The lower values of DHEAS in ex steroid users is surprising, but suggests a delayed recovery of adrenal androgen secretion following cessation of steroid treatment as reported in a patient by Cutler et al. ${ }^{27}$

In summary, we have found low levels of DHEAS in a large group of postmenopausal women with RA but normal levels of oestradiol and SHBG. As DHEAS values did not correlate with disease activity, we cannot explain these findings on the basis of the effects of chronic illness on androgen metabolism. Dynamic studies would help in our further understanding of the metabolism of androgens in RA, their possible interactive role on pathological mechanisms and their potential therapeutic role in RA.

We are grateful to all the staff involved with DEXA scanning and to the doctors and general practitioners whose patients were recruited. 
1 Masi A T, Josiprovic D B, Jefferson W E. Low adrenal androgenic-anabolic steroids in women with rheumatoid arthritis: gas-liquid chromatographic studies of $\mathrm{RA}$ patients and matched nomal control women indicting patients and matched normal control women indicating Arthritis Rheum 1984; 14: 1-22.

2 Semple C G, Gray C E, Beastall G H. Adrenal androgens and illness. Acta Endocrinol (Copenh) 1987; 116: 155-60.

3 Zumoff B, Bradlow H L, Gallagher T F, Hellman L Decreased conversion of androgens to normal 17-ketosteroid metabolites: a non-specific consequence of illness. F Clin Endocrinol Metab 1971; 32: 824-32.

4 Nestler J E, Clore J N, Blackard W G. Metabolism and actions of dehydroepiandrosterone in humans. $₹$ Steroid Biochem Mol Biol 1991; 40: 599-605.

5 Sambrook P N, Eisman J A, Champion E D, Pocock N A. Sex hormone status and osteoporosis in postmenopausal women with rheumatoid arthritis. Arthritis Rheum 1988; 31: 973-8.

6 Feher K G, Feher T, Meretey K. Interrelationship between the immunological and steroid hormone parameters in rheumatoid arthritis. Exp Clin Endocrinol 1986; 87: $38-42$.

7 Spector T D, Perry L A, Tubb G, Huskisson E C. Androgen status of females with rheumatoid arthritis. Br $\mathcal{F}$ Rheumatol 1987; 26: 315-6.

8 Cutolo M, Balleari E, Givsti M, Monachesi M, Accardo S. Sex hormone status in women suffering from rheumatoid arthritis. F Rheumatol 1986; 13: 1019-23.

9 Nordin B E C, Robertson A, Seamark R F, et al. The relation between calcium absorption, serum dehydroepiandrosterone and vertebral mineral density in postmenop $651-7$

10 Spector T D, Thompson P W, Perry L A, McGarrigle $\mathrm{H} \mathrm{H}$, Edwards A C. The relationship between sex steroids and bone mineral content in women soon after the menopause. Clin Endocrinol (Oxf) 1991; 34: 37-41.

11 Taelman P, Kaufman J M, Janssens X, Vermeulen A. Persistence of increased bone resorption and possible role of dehydroepiandrosterone as a bone metabolism determinant in osteoporotic women in late determinant in osteoporotic wome

12 Hall G M, Spector T D, Griffin A J, Jawad A S M, Hall M L, Doyle D V. The effect of rheumatoid arthritis and
steroid therapy on bone density in postmenopausal steroid therapy on bone density

13 Cutolo M, Balleari E, Giusti M, Monachesi M, Accardo S. Sex hormone status of male patients with rheumatoid arthritis: evidence of low serum concentrations of testosterone at baseline and after human chorionic gonadotropin stimulation. Arthritis Rheum 1988; 31: 1314-7.

14 Gordon D, Beastall G H, Thomson J A, Sturrock R D. Androgenic status and sexual function in males with rheumatoid arthritis and ankylosing spondylitis. $Q \mathcal{f} \mathrm{Med}$ 1986; 60: 671-9.

5 Spector T D, Perry L A, Tubb G, Silman A J, Huskisson E C. Low free testosterone levels in rheumatoid arthritis. Ann Rheum Dis 1988; 47: 65-8.

16 Rosenfeld R S, Hellman L, Gallagher T F. Metabolism and interconversion of dehydroepiandrosterone and interconversion of dehydroepiandrosterone and 19hydroepiandrost

17 Vaitukaitis J L, Dale S L, Melby J C. Role of ACTH in the secretion of free dehydroepiandrosterone and its sulphate ester in man. 7 Clin Endocrinol Metab 1969; 29: 1443-7.

18 Vermeulen $A$. The hormonal activity of the postmenopausal ovary. $\mathcal{F}$ Clin Endocrinol Metab 1976; 42: 247-53.

19 Haning R V, Flood C A, Hackett R J, Loughlin J S, McLure N, Longcope C. Metabolic clearance rate of dehydroepiandrosterone sulphate, its metabolism to testosterone, and its intrafollicular metabolism to testosterone, and its intrafollicular metabolism to dihydrotestosterone in vivo $\{$ Clin Endocrinol Metab 1991 ; dihydrotestost

20 Grodin J M, Siiteri P K, MacDonald P C. Source of estrogen production in postmenopausal women. $f$ Clin Endocrinol Metab 1973; 36: 207-14.

21 Daynes R A, Dudley D J, Araneo B A. Regulation of murine lymphokine production in vivo. Dehydroepiandrosterone is a natural enhancer of interleukin 2 synthesis by helper T cells. Eur f Immunol 1990; 20: 793 .

22 Risdon G, Moore T A, Kumar V, Bennett M. Inhibition of murine killer cell differentiation by dehydroepimurine killer cell differentiation by

23 Spector T D, Perry L A, Jubb R W. Endogenous sex steroid levels in women with generalised osteoarthritis Clin Rheumatol 1991; 10: 316-9.

24 Chikanza I C, Petrou P, Kingsley G, Chrousos G, Panayi G S. Defective regulation of the hypothalamic-pituitaryadrenal (HPA) axis in rheumatoid arthritis (RA) is not a consequence of chronic inflammation per se. [abstract]. Brf Rheumatol 1992; 31: 28.

25 Bijlsma J W J, Thijssen J H H, Huber-Bruning O, Kater I. Sex hormones in active rheumatoid arthritis [abstract]. In: XVI International Congress of Rheumatology Sydney. 1985; 683: 371 .

26 Yamaji T, Ishibasi M, Takau F, Itbashi A, Katayama S, Ishii J. Serum dehydroepiandrosterone sulphate concentrations in secondary adrenal insufficiency. $\tilde{f}$ Clin Endocrinol Metab 1987; 65: 448-51.

27 Cutler G B, Davis S E, Johnson-Baugh R E, Loriaux D L. Dissociation of cortisol and adrenal androgen secretion in patients with secondary adrenal insufficiency. $\mathcal{f}$ Clin Endocrinol Metab 1979; 49: 604-9.

28 Judd H L, Judd G E, Lucus W E, Yen S S C. Endocrine function in the postmenopausal ovary: concentration of androgens and estrogens in ovarian and peripheral vein blood. F Clin Endocrinol Metab 1974; 39: 1020-4. 